\title{
A OBJETIFICAÇÃO SEXISTA DA MULHER NAS RELAÇÕES DE CONSUMO À LUZ DA TEORIA FEMINISTA DE MACKINNON
}

\section{WOMEN'S SEXIST OBJECTIFICATION IN CONSUMER RELATIONS CONSIDERING MACKINNON'S FEMINIST THEORY}

Recebimento: 27 out. 2019

Aceitação: 6 abr. 2021

\author{
Dennis Verbicaro \\ Doutor em Direito \\ Afiliação institucional: Universidade Federal do Pará - UFPA - (Belém, PA, Brasil) \\ Lattes iD: http://lattes.cnpq.br/9961080231553419 \\ Email: dennisverbicaro@bol.com.br \\ Janaina Vieira Homci \\ Mestra em Direito \\ Afiliação institucional: Universidade Federal do Pará - UFPA - (Belém, PA, Brasil) \\ Lattes iD: http://lattes.cnpq.br/3881294450621672 \\ Email: janainanasvieira@gmail.com
}

Como citar este artigo / How to cite this article (informe a data atual de acesso / inform the current date of access):

VERBICARO, Dennis; HOMCI, Janaina Vieira. A objetificação sexista da mulher nas relações de consumo à luz da teoria feminista de MacKinnon. Revista da Faculdade de Direito UFPR, Curitiba, v. 66, n. 2, p. 51-68, maio/ago. 2021. ISSN 2236-7284. Disponível em: https://revistas.ufpr.br/direito/article/view/69906. Acesso em: 31 ago. 2021. DOI: http://dx.doi.org/10.5380/rfdufpr.v66i2.69906.

\section{RESUMO}

Este artigo tem por objetivo demonstrar, à luz da teoria feminista de Catharine MacKinnon, como a cultura de dominação/submissão da sociedade patriarcal exerce influência nas relações de consumo e na pornografia. Tal cultura significa a objetificação da mulher, transformando-a em mero ser vinculado à sexualidade para satisfação de desejos masculinos, e leva à natural aceitação da perspectiva dominação/submissão em todos os aspectos da vida em sociedade e a reflexos nas relações consumeristas, havendo desrespeito a diversos princípios, como o da igualdade e o de reconhecimento da mulher como sujeito de direito. Ressalta-se que essa caracterização, tanto nas relações consumeristas, quanto na pornografia, expõe a mulher a dano coletivo, ensejando medidas de proteção - seja pelo Estado, seja pela conscientização ante maior participação cívica feminina. Nesse contexto, primeiro será feita uma análise da sociedade patriarcal e sexista e de como ambas influenciam as relações de consumo. Após, analisar-se-á a teoria feminista de Catharine MacKinnon e a estrutura social de poder, sob enfoque da sexualidade, para, então, realizar-se um estudo comparativo entre pornografia, como concretização da coisificação da mulher, e relações consumeristas sexistas. Esta pesquisa possui natureza exploratória e se utiliza de referencial nacional e estrangeiro. 


\title{
PALAVRAS-CHAVE
}

Relações de consumo. Sexismo. Feminismo. Pornografia. MacKinnon.

\begin{abstract}
This article aims to demonstrate, in the light of Catharine MacKinnon's feminist theory, how the culture of domination/submission of the patriarchal society exerts an influence on consumer relations and pornography. Such a culture means the objectification of women, transforming them into a mere being linked to sexuality for the satisfaction of male desires, and leads to the natural acceptance of the domination/submission perspective in all aspects of life in society and reflexes on consumerist relationships, with disrespect to various principles, such as equality and recognition of women as subjects of rights. It is noteworthy that this characterization, both in consumer relations and in pornography, exposes women to collective harm, entailing protective measures - either by the State, or through awareness of greater female civic participation. In this context, first an analysis of the patriarchal and sexist society and how both influence consumer relations will be carried out. Afterwards, the feminist theory of Catharine MacKinnon and the social structure of power will be analyzed, under the focus of sexuality, to then carry out a comparative study between pornography, as the realization of the objectification of women, and sexist consumerist relationships. This research has an exploratory nature and uses national and foreign references.
\end{abstract}

\section{KEYWORDS}

Consumer relations. Sexism. Feminism. Pornography. MacKinnon.

\section{INTRODUÇÃO}

Para Arendt (2007), a vida ativa é designada por três atividades fundamentais: o labor, o trabalho e a ação. Tem-se por labor a atividade correspondente ao processo biológico do corpo humano, cujo crescimento espontâneo, metabolismo e eventual declínio estão relacionados com as atividades vitais da vida. No que diz respeito ao trabalho, é a atividade correspondente ao artificialismo da existência humana, que produz um mundo artificial de coisas, diferente de qualquer ambiente natural. Já a ação corresponde à condição humana de pluralidade, é a condição de ser "sem que ninguém seja igual a qualquer pessoa que tenha existido, exista ou que venha a existir” (ARENDT, 2007, p. 16).

O labor e o consumo são dois estágios do processo de imposição, ao homem, de cumprimento de suas necessidades de vida. No entanto, esse processo não significou a emancipação do homem e sim a sua servidão voluntária (LA BOÉTIE, 2016), diante da constante busca pela satisfação de necessidades artificiais, ou seja, criadas pelo mercado:

Quanto mais fácil se tornar a vida numa sociedade de consumidores ou de operários, mais difícil será preservar a consciência das exigências da necessidade que a impele, mesmo quando a dor e o esforço - manifestações externas da necessidade - são quase imperceptíveis. O perigo é que tal sociedade, deslumbrada ante a abundância de sua crescente fertilidade e presa ao suave funcionamento de um processo interminável, já não seria capaz de reconhecer 
a sua própria futilidade - a futilidade de uma vida que "não se fixa nem se realiza em coisa alguma que seja permanente, que continue a existir após terminado o labor” (ARENDT, 2007, p. 147-148).

No entanto, a mulher continuou, sob uma perspectiva privada (ou seja, voltada à família) em uma situação de dominação/exploração em relação ao homem, justificada pela referência particularista e emocional (KYMLICKA, 2006). Neste sentido, a sociedade é sexista quando baseada em valores masculinos, o que favorece sistematicamente os homens ao definir trabalhos, méritos e coisas. Isso, por sua vez, resulta em um sistema que identifica culturas no qual a masculinidade é associada à renda e a feminilidade é definida como serviços sexuais e domésticos. Elas são vinculadas a figuras passivas e subordinadas à supremacia masculina, em que as diferenças de gênero são relevantes para a distribuição de benefícios, trazendo desvantagens sistemáticas às mulheres (KYMLICKA, 2006).

Para Beauvoir (1970), a natureza feminina não explica a condição de subordinação destinada a mulher. No entanto, pelo processo de construção social e antropocêntrica, o homem é considerado uma categoria positiva, o eu, o sujeito, e a mulher, uma categoria negativa, o não eu, o outro, o objeto:

[...] o triunfo do patriarcado não foi nem um acaso nem o resultado de uma revolução violenta. Desde a origem da humanidade, o privilégio biológico permitiu aos homens afirmarem-se sozinhos como sujeitos soberanos. Eles nunca abdicaram o privilégio; alienaram parcialmente sua existência na Natureza e na Mulher, mas reconquistaram-na a seguir. Condenada a desempenhar o papel do Outro, a mulher estava também condenada a possuir apenas uma força precária: escrava ou ídolo, nunca é ela que escolhe seu destino (BEAUVOIR, 1970, p. 97).

Para a autora, as próprias mulheres enxergam-se como outro por não possuírem meio concreto para se constituírem como unidade, não apresentam história una, comum e singular, bem como, aceitam o papel do não eu.

Dworkin (1974) aduz que a mulher é criada para ser uma figura passiva e dominada. Os ditos “contos de fadas” são exemplos da objetificação feminina, ao caracterizarem a mulher voltada ao lar, à família, à reprodução, sob uma relação de exploração, submissão e dominação quanto ao homem. Kymlicka (2006) destaca que características patriarcais são fortes e presentes em todos os aspectos da sociedade. Estão, portanto, presentes inclusive nas relações de consumo.

A desigualdade das relações de poder e, consequentemente, discriminação de gênero se fazem presentes na sociedade em todas as relações, sejam elas privadas ou públicas. Apesar das conquistas feministas, os homens são considerados superiores, constituindo-se no primeiro sexo. A mulher, por sua vez, é o segundo sexo, submissa, discriminada e desvalorizada. Tal ideia reforçada pela perspectiva dominação/submissão é empregada na pornografia. A referida discriminação 
também é percebida nas relações consumeristas, uma vez que, ao tratá-la como mero objeto, inferioriza-se e discrimina-se a mulher, apagando a sua individualidade e personalidade, desvalorizando-a e a tornando serva do consumo (VERBICARO; VERBICARO; AZEVEDO, 2019). Essa servidão está caracterizada nos inúmeros padrões destinados à mulher, na qual se dedica com vigor a realizá-los diante da possibilidade de exclusão.

Esta pesquisa justifica-se para demonstrar como a mulher é objetificada na sociedade. Para feministas radicais, como MacKinnon (1995, 2013, 2016), a pornografia reforça a coisificação da mulher ao vincular a sua figura à sexualidade para satisfação dos desejos sexuais masculinos. A consequência disso é a natural aceitação de tal perspectiva em todos os aspectos relacionais da vida em sociedade, causando reflexos, inclusive, nas relações consumeristas, o que gera o desrespeito a diversos princípios, como: dignidade, igualdade, liberdade e reconhecimento do feminino como sujeito.

Para o desenvolvimento desta pesquisa, o método utilizado é o hipotético-dedutivo, sendo a fonte de conhecimento sedimentada inicialmente no estudo doutrinário dos referenciais teóricos selecionados como guias de análise do objeto. Na primeira seção, será realizado um estudo sobre sociedade patriarcal e sexista, para observar como ambas influenciam nas relações de consumo. Posteriormente, será analisada a teoria feminista de Catharine MacKinnon (1995, 2013, 2016), à luz da sexualidade e, então, a objetificação da mulher, para identificar traços entre a pornografia, como concretização da coisificação feminina, e a percepção sexista nas relações consumeristas.

\section{O PATRIARCADO, O SEXISMO E AS RELAÇÕES DE CONSUMO}

A dominação da figura feminina por meio do patriarcado é um fenômeno social. Define-se patriarcado como um ajuste masculino para garantir a opressão feminina, sendo que "as relações hierárquicas entre homens, assim como a solidariedade existente entre eles, capacitam a categoria constituída por homens a estabelecer e manter o controle sobre as mulheres” (SAFFIOTI, 2015, p. 111). Nesse sistema, mulheres são objetos de satisfação sexual dos homens e reprodutoras de novos herdeiros e novas reprodutoras (SAFFIOTI, 2015).

Quando o homem passou a criar animais, percebeu-se que quanto mais filhos havia, mais auxílio ele detinha para cultivar terras. Consequentemente, entendeu-se a natureza como controlada e dominada. Isso foi essencial para se estabelecer a relação de dominação/exploração entre homens e mulheres, uma vez que elas passaram a ser vistas como máquinas de reprodução (SAFFIOTI, 2015). 
O controle gerado pela dominação/exploração passou a ser a figura principal de todas as áreas de convivência social na estrutura de poder patriarcal. No que tange ao sexismo, quem está investido do poder patriarcal está autorizado a discriminar categorias, marginalizando-as. Trata-se de uma relação de dominação/subordinação que "reside no vínculo arbitrariamente estabelecido entre fenômenos: voz grave significa poder, ainda que a pessoa fale baixo” (SAFFIOTI, 2015, p. 132).

A cultura predetermina o papel de cada um, os comportamentos, o que está disposto a conhecer e a sentir. Na cultural patriarcal, as mulheres nasceram para um papel sexual, uma figura passiva e submissa no cenário cultural homem/mulher, presa na busca pela beleza e a um padrão estético para satisfação do homem (DWORKIN, 1974).

Com o crescimento capitalista, a acumulação de capital situa-se como eixo central das coisas. O progresso da acumulação depende de mão de obra excedente, da existência de quantidade necessária de meios de produção e da existência de mercado para absorver a quantidade excedente de mercadoria produzida (HARVEY, 2005). O mercado de consumo é criado antes mesmo da produção do bem. Nesse sentido, o capitalismo é permeado de dispositivos ${ }^{1}$ de controle sobre as pessoas.

Para Silva (2018), os dispositivos sempre existiram. No entanto, com a necessidade de expansão do mercado, eles estão mais presentes, a ponto de nenhum momento na vida das pessoas deixar de ser controlado, moldado ou corrompido. Enquanto houver a necessidade de busca de mercado de consumo, haverá a necessidade de controle, padronização e transformação dos seres em consumidores.

Nesse sentido, a necessidade de expansão do mercado de consumo e a criação de dispositivos de controle fortaleceram a fixação de padrões culturais sexistas, passando a interferir nas relações de consumo. A liberdade tornou-se apenas um discurso retórico, em que as mulheres continuam, em relação ao patriarcado, como figuras expostas a exploração, dominação e submissão, algo reforçado pelo mercado.

Destaca-se que, no Brasil, a legislação consumerista tem como seu princípio basilar a vulnerabilidade, conforme artigo 4º , do Código de Defesa do Consumidor (CDC) (BRASIL, 1990). Todos os consumidores são considerados vulneráveis, pelo próprio desequilíbrio na relação, quando comparados com os fornecedores. No entanto, por características (a)temporais, alguns grupos apresentam a sua condição de vulnerabilidade agravada (BAROCELLI, 2017). Considerando a figura feminina, o sexismo tornou-se uma linguagem frequentemente utilizada pelo mercado para dialogar

1 Para Silva (2018), dispositivo diz respeito a um processo de subjetivação que visa, mediante uma série de práticas e de discursos, à criação de corpos dóceis, mas livres, que assumem a sua identidade e a sua condição de "liberdade" por meio do assujeitamento. 
com a sociedade consumerista mediante caráter apelativo e enfoque depreciativo dessa figura. A discriminação e o crescente assédio discriminatório de gênero são frequentes, o que possibilita tal agravamento da vulnerabilidade da mulher nessas relações.

O tratamento estabelecido divide-se em falar “de mulher” e “com a mulher” (VERBICARO; ALCÂNTARA, 2017). A primeira ação tende a estereotipá-la a partir de uma imagem estética deturpada por meio de uma sexualidade apelativa. A segunda revela-se pela imposição da mulher a padrões inalcançáveis de beleza e comportamento:

São modelos de valores, de beleza, de felicidade que nos vedem - e que podemos adquirir até em suaves prestações mensais, para comprar produtos, procedimentos, tratamentos, que nos prometem fazer chegar a ideais diurnamente destilados em imagens positivadas, que nos assaltam a cada esquina, a cada revista, a cada programa e que, rapidamente, introjetamos como sendo o "nosso ideal” (MORENO, 2017, p. 32).

Dworkin (1974) afirma que a fixação de padrões impostos pela cultural patriarcal transforma a mulher em mero objeto para lascívia masculina. Expõe que as mulheres eram obrigadas a seguir padrões totalitários de beleza e o fascismo sexual desenfreado. Na China, por exemplo, enquanto menor o pé, maior a admiração e melhor o casamento. Para isso, aproximadamente, aos sete anos de idade, as meninas eram mutiladas mediante o uso de faixas, sapatos apertados e até procedimentos para deixar o pé entre oito e dez centímetros de comprimento:

Milhões de mulheres, ao longo de um período de 1.000 anos, foram brutalmente aleijadas, mutiladas, em nome do erotismo.

Milhões de seres humanos, ao longo de um período de 1.000 anos, foram brutalmente aleijados, mutilados, em nome da beleza.

Milhões de homens, ao longo de um período de 1.000 anos, deleitaram-se em fazer amor devotado à adoração do pé amarrado.

Milhões de homens, durante um período de 1.000 anos, cultuaram e adoraram o pé amarrado. Milhões de mães, durante um período de 1.000 anos, aleijaram brutalmente e mutilaram suas filhas pelo bem de um casamento seguro.

Milhões de mães, durante um período de 1.000 anos, aleijaram e mutilaram brutalmente suas filhas em nome da beleza. (DWORKIN, 1974, p. 111-112, tradução nossa).

Atualmente, não é diferente. Padrões de beleza descrevem termos precisos do relacionamento da mulher com seu corpo. Todas as partes do corpo feminino durante a sua vida são tocados. Os cabelos são tingidos, alisados, as sobrancelhas são tiradas e tatuadas, cílios enrolados, pelos depilados, queimados por laser, hormônios masculinos são prescritos ou instalados mediante chips na pele, o corpo sujeito a constantes modificações por meio de procedimentos estéticos e cirúrgicos em nome do padrão fixado pela sociedade... São inúmeros os processos em busca desse modelo imposto, sendo o seu corpo uma matéria a ser constantemente corrigida. Ela já nasce com defeitos que precisam ser acertados, e o tempo também lhe fornece marcas que maculam o padrão de 
beleza estabelecido (VERBICARO; VERBICARO; AZEVEDO, 2019). Não está, nesse sentido, tão longe da perspectiva chinesa de enfaixamento dos pés. Conforme Dworkin (1974), a dor é fundamental para o processo de crescimento da mulher e isso não é acidental diante de um fetiche de uma perspectiva cultural patriarcal.

A fixação de padrões torna as mulheres seres genéricos, psicológica e economicamente fragilizados, "sendo discriminadas e obrigadas a alegrar e enfeitar o mundo, atendendo aos padrões estéticos vigentes e tendo suas capacidades intelectuais tratadas como características secundárias, a serem admiradas apenas se a função estética for devidamente cumprida” (VIANNA, 2005, p. 3).

No mesmo sentido, Verbicaro e Alcântara (2017) aduzem que, quando relacionado ao entretenimento, o público feminino recebe "preço especial” por se entender que a maior quantidade de mulheres numa festa aumenta o público masculino. Nesse sentido, mulheres são vistas como meros objetos, commodities, algumas consideradas mais caras que outras (DWORKIN, 1974). São coisas assediadas e discriminadas em função do sexismo, existente na cultura patriarcal e reforçado pelo mercado, nas relações de consumo.

\section{ANOTAÇÕES SOBRE A TEORIA FEMINISTA DE MACKINNON E A VISÃO DA ESTRUTURA SOCIAL DE PODER}

O movimento feminista caracteriza-se em ondas: a primeira aduz o ataque às diferenças discriminatórias e insustentáveis entre homens e mulheres, à diferença no trabalho e na participação da condução da vida política da comunidade. A segunda onda está centralizada nas questões privadas e no corpo da mulher, com foco, portanto, nas diferenças relevantes entre os sexos. A terceira onda reivindica as diferenças entre as próprias mulheres (SIQUEIRA, 2015).

Com a união do feminismo com a teoria política, esta adentra no direito por meio da promoção da prática jurídica feminista em casos individualizados. No entanto, ao entender que a igualdade defendida pelo feminismo liberal não foi suficiente para eliminar a situação de inferioridade das mulheres em relação aos homens em razão do foco substancialmente individualista, o feminismo radical entendeu que as demandas por maior participação na vida pública e igualdade jurídica/política não alteraram a estrutura das relações de poder existente entre os gêneros, sendo homem e mulher categorias "políticas, com comportamentos, desejos e características moldados culturalmente" (TAVARES; LOIS, 2016, p. 158).

Nessa linha, a teoria feminista de MacKinnon tem por base o feminismo radical e explora a relação de dominação/submissão das mulheres perante os homens, sendo vistas como mero objeto na 
relação. Para MacKinnon (1995, 2013), a sexualidade está para o feminismo como o trabalho está para o marxismo. Para a teoria marxista, a sociedade é fundamentalmente construída pelas relações de produção para sobrevivência humana. O trabalho é um processo social de formação e transformação da sociedade, em que as pessoas compreendem seu papel social.

Para MacKinnon (2016), apesar de haver um ponto em comum entre as teorias marxistas e feministas, o feminismo critica o marxismo por este ter sua definição e seus elementos voltados à perspectiva e experiência masculinas, ignorando, consequentemente, as percepções distintivas entre os sexos. Já os marxistas afirmam que o feminismo não exerce uma divisão de classe entre as mulheres e ofusca o proletariado.

MacKinnon (1995, 2016) destaca que o ponto principal do feminismo é confrontar a realidade da condição feminina, partindo do exame das experiências, tomadas como ponto de partida para mudança individual e coletiva. A conscientização é a principal técnica de análise, estrutura de organização, método prático e teórico da mudança social. Tal consciência está na dor, no isolamento e na objetificação comum às mulheres:

\footnotetext{
Por meio da conscientização, as mulheres compreendem a realidade coletiva da condição das mulheres a partir de dentro da perspectiva dessa experiência, e não de fora. A pretensão de que uma política sexual existe e é socialmente fundamental é alicerçada na pretensão do feminismo para a perspectiva das mulheres e não a partir dela. Sua pretensão à perspectiva das mulheres é sua pretensão à verdade (MACKINNON, 2016, p. 829).
}

MacKinnon (1995, 2016) identifica a sexualidade como esfera social primária do poder masculino. A sexualidade está presente em todos os aspectos da vida da mulher e tal característica é a principal razão da relação de submissão, dominação e exploração existente entre os gêneros. Para comprovar a afirmativa, MacKinnon (2013) menciona que cerca de 85\% de todas as mulheres que trabalham já passaram por algum tipo de assédio sexual ao longo da vida profissional. Observa-se, assim, que reivindicar a sexualidade é questionar o olhar construído sobre mulheres como objetos de prazer e desejos masculinos.

A sexualidade organiza a sociedade em dois sexos, homem e mulher, sendo tal divisão a base das relações, uma vez que é dela que se forma o processo social que cria, organiza, expressa e dirige o desejo (MACKINNON, 1995, 2013). MacKinnon (2013, p. 234) confirma a assertiva ao afirmar que "assim como a expropriação organizada do trabalho de alguns para o benefício de outros define uma classe de trabalhadores, a expropriação organizada pela sexualidade de algumas para o uso dos outros define o sexo mulher”. A sexualidade, portanto, cria as relações hierárquicas de poder.

O marxismo e o feminismo são teorias sobre o poder e sua distribuição desigual. O feminismo é uma teoria sobre como a erotização da dominação e da submissão cria o gênero, 
estabelecendo a relação entre homem e mulher na forma social. O ponto de vista masculino se impôs ao mundo e, consequentemente, demanda uma maneira de conhecê-lo. Assim, o gênero é uma questão de dominação e estrutura social. Homens e mulheres são igualmente diferentes, mas não igualmente poderosos (MACKINNON, 2013). Para MacKinnon (2016), há uma divisão social de poder, na qual os homens criam o mundo a partir de suas perspectivas, o que passa, consequentemente, a ser a verdade descrita.

A desigualdade entre os poderes é o ponto crucial para construção de uma sociedade dominada por homens. Assim, não há neutralidade quando mulheres estão inseridas em uma sociedade direcionada à figura masculina (MACKINNON, 1995). Nessa perspectiva, o Estado, como parte do sistema, não questiona a violência constante e cotidiana sofrida pela mulher e o direito, enquanto produto do Estado, reforça a divisão de poderes (TAVARES; LOIS, 2016). Assim, a teoria do direito é uma teoria masculina do direito, uma vez que a sociedade, moldada por uma ideologia patriarcal, apresentará normas jurídicas que vão ao encontro da relação submissão/dominação entre mulher e homem:

O direito, em que pese a exposição de sua feição sexista, segue, majoritariamente, tendendo à conservação da interpretação jurídica que exiba no Estado o espelho da sociedade sem problematizar a divisão hierárquica dos sexos, o que empresta objetividade à epistemologia, dissemina a experiência masculina como a experiência humana e assegura a manutenção das posições de poder já existentes. As normas formais do Estado iluminam a perspectiva masculina como um verdadeiro projeto político a partir do sexo, constituindo uma ideologia que tem como instrumentos as condições inferiores influentes também nos campos econômico, social, psicológico, emocional etc. (TAVARES; LOIS, 2016, p. 168).

Neste sentido, questiona-se a universalidade da norma, uma vez que ela é criada sob a realidade masculina. Normas, com sua perspectiva restrita, frequentemente são hostis à proteção da mulher (MACKINNON, 1995, 2016).

A teoria feminista tem por objetivo exatamente trazer a consciência crítica, uma vez que "se o poder masculino torna o mundo o que ele 'é', teorizar essa validade requer captá-la a fim de submetê-la à crítica, e daí, à mudança” (MACKINNON, 2013, p. 245). A teoria ainda prevê a aplicação do método marxista à concepção feminista, incluindo a visão histórica como um fluxo de pensamento crítico, chamando-o, assim, de pós-marxismo, destacando que o feminismo não é percebido como algo vinculado ao método, mas como uma coleção de fatores, queixas e questões que, ao serem considerados em conjunto, explicam o infortúnio do sexo feminino (MACKINNON, 1995, 2016).

Para Beltrán et al. (2008), MacKinnon é uma das autoras mais conhecidas do feminismo radical americano, cujo objeto de atenção, de elaboração teórica e de reivindicação está situado no 
âmbito jurídico. Destacam ainda que MacKinnon desenvolve debates em torno da pornografia, pleiteando, inclusive, a sua proibição.

A perspectiva feminista de MacKinnon (1995, 2013, 2016), portanto, internaliza a sexualidade como forma de poder e, o gênero, como interpretação social, colocando-o como "o eixo de desigualdade entre os sexos” (MACKINNON, 1995, p. 200, tradução nossa). A teoria feminista tem por objetivo subjetivar a ciência para incluir a visão feminina, uma vez que a objetividade é produto masculino.

Para MacKinnon (1995), é necessária uma nova teoria, uma nova relação entre vida e direito, que contemple a inexistência de neutralidade do último como reflexo de uma política de dominação/submissão, influenciada por uma cultura patriarcal. Tal teoria seria uma forma efetiva para se buscar a igualdade e o reconhecimento da mulher, destacando-se que "o método feminista é a conscientização (consciousness raising): a reconstrução coletiva e crítica do significado da experiência social das mulheres, como as mulheres a vivem” (MACKINNON, 2016, p. 837).

\section{A OBJETIFICAÇÃO DA MULHER: ENTRE O SEXISMO NAS RELAÇÕES DE CONSUMO E A PORNOGRAFIA, SOB A PERSPECTIVA DE MACKINNON}

A pornografia é um produto cultural estabelecido no tempo e no espaço em que atua, sendo indissociável do momento histórico. No final do século XVIII, viu-se uma mudança da pornografia, de filosófica e política para comercial, cujo principal anseio é o mercado (SANTANA, 2014, p. 30).

O feminismo radical "postula que a origem da subordinação e opressão feminina está no patriarcado, ou seja, no poder da supremacia masculina, justificado pelas diferenciações sexuais inatas a cada sexo” (SANTANA, 2014, p. 17), sendo a pornografia narrativa voltada ao público masculino que ressalta a posição submissa/dominada da mulher. É uma forma de materialização do contrato patriarcal entre homens e mulheres, de perpetuação da lógica de dominação, na qual elas são vistas como meros objetos.

Para Dworkin (1981), a pornografia é uma violação dos direitos civis das mulheres, uma forma de discriminação sexual, que estabelece subordinação sexual e social feminina aos homens. Mulheres são transformadas em objetos sexuais, em coisas ou mercadorias, pelo reforço das hierarquias de poder que moldam e induzem formas de desejos cesaristas.

A objetificação faz da sexualidade uma realidade material na vida das mulheres, para além da natureza psicológica ou ideológica. Como o valor de uma mercadoria, a desejabilidade sexual das mulheres torna-se um fetiche, feita para parecer espontânea, inerente, independente da relação social 
que a cria (MACKINNON, 2016, p. 833). A pornografia é a concretização da sociedade pautada na sexualidade como fonte de poder e discriminação.

No mesmo sentido, a pornografia, para MacKinnon (1995), é a indústria dominada por homens que fixa padrões para transformar mulheres em objetos A pornografia hardcore, em que o pênis ereto é destacado (DWORKIN; MACKINNON, 1988), é implementação da ideia de submissão feminina para satisfação masculina, sendo o homem o sujeito e a mulher, a coisa.

Para o movimento feminista antipornografia, a indústria pornográfica trabalha com materiais gráficos sexualmente explícitos que subordinam mulheres e vendem a percepção de que elas são meros seres descartáveis. Além disso, essa indústria enfatiza a desigualdade entre homens e mulheres, uma vez que elas são humilhadas, segregadas e violadas, perpetuando a ideia, aos expectadores, de que elas gostam de ser submissas, dominadas e forçadas a práticas sexuais (DWORKIN; MACKINNON, 1988). A consequência disso é a naturalização da sexualização da figura feminina de forma discriminatória.

A supremacia masculina sobre a feminina no que diz respeito à relação de poder se dá por alguns aspectos: força física, afirmação metafísica de si mesmo, capacidade de causar medo, poder de nomeação, de possuir, econômico e do sexo. Na pornografia, o poder masculino reforça outras expressões de poderes, como: física, de terror, de dominação, de possuir, do dinheiro e do sexo (DWORKIN, 1981).

No mesmo sentido, publicidades sexistas expressam a sexualização feminina quando, em campanhas como "E você, está esperando o que para ter a sua primeira vez com uma devassa?" (NOVAS, 2013) e “Esqueci o não em casa!” (VERBICARO; ALCÂNTARA, 2017), ambas vinculadas a imagens de mulheres, há a nítida tentativa de enquadrar a figura feminina como objeto sexual.

Ainda, a prática de diferenciação entre preços é outro exemplo de desigualdade nas relações de poder e de discriminação entre consumidores, uma vez que se baseia em conceitos de gênero, o que acaba por confirmar a objetificação e sexualização da figura feminina na sociedade, dificultando o acesso e o estabelecimento da autonomia social, da igualdade e da proteção da dignidade da mulher.

É fato que quando a nota técnica da Secretaria Nacional do Consumidor (Senacon) $\mathrm{n}^{\circ}$ 11/2019 retificou o entendimento emitido anteriormente e afirmou que a taxação com base no gênero seria válida, determinando que a mulher pode ser utilizada como um atrativo masculino, o Estado, nesse sentido, perpetuou a ideia de coisificação da mulher para satisfação da lascívia masculina. Na mesma linha em que a pornografia é vista pelas feministas radicais, o mercado e o Estado, aqui, 
reforçam a perspectiva de dominação masculina sobre a figura feminina, para satisfação de desejos carnais.

A publicidade tem um papel essencial no processo de naturalização das relações de poder e dominação que envolve questões de gênero, por meio de representações que fortalecem e solidificam papéis sociais de homens e mulheres. Na comunicação publicitária, são fixados padrões que reafirmam a coisificação da mulher, uma vez que ela, em 58\% dos casos, é demonstrada como um “objeto de desejo”, além de ser retratada como coadjuvante ou como prêmio associado ao bem de consumo:

\footnotetext{
A mulher “escrava da beleza” reforça a ideia do corpo feminino, como corpo percebido, cujo controle está no embelezamento, na conservação da juventude com a intenção de se sentir desejável e agradar o outro. Numa associação direta com a cultura de consumo, conforme os produtos de estética se tornaram acessíveis a todos os bolsos, embelezar-se deixou de ser um luxo e passou a ser um dever da mulher (FREIRE OLIVEIRA-CRUZ, 2017, p. 185).
}

Na mesma linha, a sociedade de consumo, mediante a publicidade, exerce um processo de objetificação do corpo feminino, como se este fosse a própria mercadoria. Nessa perspectiva, a mulher, tanto nas relações de consumo, como na pornografia, é tratada como um objeto na maneira como se veste e como se comporta, para seguir um padrão que não necessariamente satisfaz as suas necessidades sociais e emocionais.

Não há autonomia quando se está inserida numa sociedade duplamente opressora, seja pelo patriarcado, seja no sistema capitalista. Conforme Dworkin e MacKinnon (1988) aduziram, se a pornografia, ao objetificar a mulher, é definida como algo sexualmente excitante, qualquer modelo que segue tal premissa pode ser comparado ao pornográfico, como a violência contra mulheres, violação das mulheres ou sua coisificação em filmes, revistas ou comerciais.

\section{A NECESSIDADE DE CONSCIENTIZAÇÃO FEMININA E O EMPODERAMENTO DA CONSUMIDORA NO COMBATE A PRÁTICAS SEXISTAS}

Na Argentina, em comemoração ao Dia da Criança de 2018, uma rede de supermercado realizou uma campanha, na qual evidenciava o homem como construtor e a mulher, como cozinheira, destacando a percepção sexista das relações. Consequentemente, muitas mulheres manifestaram-se nas redes para retirada dessa publicidade. A repercussão foi tão negativa que a empresa se desculpou publicamente (LA PUBLICIDAD..., 2018).

No Brasil, campanha publicitária de companhia de cerveja, “Esqueci o não em casa!”, caracterizou mulheres como seres passivos, submissos aos desejos masculinos. No mesmo sentido do 
ocorrido na Argentina, diversas mulheres mobilizaram-se nas redes sociais para boicotar o produto veiculado na mensagem ofensiva (VERBICARO; ALCÂNTARA, 2017).

Na Rússia, durante a Copa do Mundo de 2018, uma rede de fastfood ofereceu prêmio equivalente a R\$ 180.000,00 e suprimento vitalício de hambúrgueres para mulheres que engravidassem de jogadores durante o evento. Posteriormente, a rede pediu desculpas publicamente, por ter se utilizado de estereótipos sexistas para promover seu produto (EMPRESA..., 2018).

Em todos os casos mencionados observam-se práticas sexistas no que diz respeito à discriminação da mulher, quando esta aparece vinculada a produtos mediante a premissa patriarcal de dominação/exploração.

Tais práticas imperam no âmbito das relações de consumo. As pink taxes² são exemplos de como o comércio se utiliza do gênero para diferenciar e onerar a mulher. A própria tributação de materiais higiênicos femininos essenciais, como absorventes, é realizada acima da média de demais produtos também considerados de higiene, sendo em torno de $25 \%$ em relação ao preço-base, com variação de valor ao longo dos anos (ALMEIDA; MARIANI; OSTETTI, 2016, p. 1). Ademais, podese ainda destacar o entendimento do Estado em não compreender como prática discriminatória a utilização da figura feminina para fixar preços dos ingressos em eventos.

Com o advento do Código de Defesa do Consumidor e a criação da Política Nacional do Consumo, a defesa do consumidor foi fortalecida. A princípio, entendeu-se que o Estado passaria a ser sujeito ativo na proteção do consumidor. No entanto, após 31 anos de vigência do Código, o Estado perdeu o seu protagonismo no âmbito da proteção, por não conseguir cumprir de forma efetiva a função de mediação de conflitos nas relações de consumo (VERBICARO; FREIRE, 2018b). Consequentemente, a própria consumidora, por meio da maior participação cívica coletiva, tem de buscar sua proteção, igualdade e reconhecimento, como nos casos em discussão.

Conforme se pode ver nos casos acima demonstrados, é inquestionável a participação ativa da mulher no combate às publicidades sexistas pelas redes sociais. A inoperância estatal exigiu o empoderamento da consumidora na luta contra práticas desleais, como, inclusive, o sexismo, nas relações de consumo. Na mesma linha, destacam Verbicaro e Freire (2018a, p. 13):

As mídias sociais relacionam-se à ideia de comunidade, na qual a participação coletiva dos cidadãos, para manter a sociabilidade e as relações de apoio, alicerça o espaço cibernético, o então ambiente Web 2.0. O nível de participação dos cidadãos, o interesse coletivo e o poder de massa possibilitado pelas redes midiáticas agrega valor democrático às comunidades, por sua vez impondo, em fluxos, novos padrões comportamentais.

2 Preços diferenciados sobre produtos similares, em razão da destinação ao gênero feminino. 
Para MacKinnon (1995, 2013, 2016), a teoria feminista tem por objetivo justamente incluir, mediante a conscientização como a principal técnica de análise, estrutura de organização, método prático e teoria da mudança social, a perspectiva feminina em todos os aspectos da vida social. É uma luta pela subjetivação da mulher, pela reconstrução coletiva e crítica do significado da experiência social das mulheres.

Assim, para MacKinnon (1995, 2013, 2016), a conscientização e a luta coletiva são instrumentos de combate à sexualização feminina, enraizada pela sociedade patriarcal. Por meio da busca coletiva de igualdade, dignidade e reconhecimento da mulher, todos os aspectos sociais inclusive, conforme os casos em discussão, das relações de consumo - mudam a visão e a estruturação social.

Percebe-se que a percepção sexista das relações de consumo é muito forte e cotidiana. No entanto, mesmo de forma lenta, tal percepção está sendo modificada pela conscientização feminina mediante o empoderamento cívico da consumidora, principalmente nas mídias sociais. MacKinnon (1995, 2013, 2016) defende a conscientização como forma de combate à sexualização da mulher e, nesse sentido, sua teoria é confirmada quando se relaciona à luta de mulheres contra publicidades estereotipadas pelas mídias sociais.

\section{CONSIDERAÇÕES ADICIONAIS}

Para Dworkin e MacKinnon (1988), a pornografia não viola apenas a mulher que participa do ato, mas toda a coletividade, por normalizar a submissão feminina e, consequentemente, ferir a humanidade, dignidade e igualdade entre gêneros. Tradicionalmente, a lei considera a pornografia uma questão privada e de moralidade pública, mas não a dano coletivo. Nesse sentido, as normas sobre pornografia vinculam-se a questões morais e não à segurança pública, pessoal e igualdade de gênero.

Dworkin e MacKinnon (1988) destacam que a lei, nessa perspectiva, está errada, uma vez que a pornografia não pode ser vinculada a aspectos meramente formais, mas, aos abusos produzidos em massa pela sua distribuição: os estupros, o assédio sexual, o abuso sexual contra crianças, o sexo e a prostituição forçados, a sexualização indesejada, o status de segunda classe, entre outros.

Para feministas radicais, a pornografia molda e reforça a concepção social da mulher, tornando normal a exploração por meio da objetificação da figura feminina. As consequências disso também se dão em níveis coletivos, quando transformam em estado natural as desigualdades entre gêneros, a dominação e submissão da mulher: 
A lei do estupro faz a suposição pornográfica de que as mulheres podem consentir no sexo forçado. A lei da guarda dos filhos aplica a definição pornográfica da mulher às mães. As mulheres que mantêm relações sexuais com um homem (ou homens) que não é o pai de seus filhos são consideradas mulheres fáceis, portanto, não são boas mães. Mães lésbicas descobriram que uma mulher que não está sendo usada sexualmente por um homem é considerada uma mulher inadequada, portanto também não é uma boa mãe. Os fracassos frequentes de tentativas sob a lei de discriminação sexual para fazer com que as mulheres recebam salários iguais aos homens quando realizam diferentes trabalhos de valor comparável permitem que definições de trabalho e escalas de pagamento continuem baseadas em definições pornográficas do papel apropriado das mulheres como subordinadas hierárquicas masculinas, como sexualmente agradáveis à vista para os homens e serviçais para necessidades masculinas (DWORKIN; MACKINNON, 1988, p. 27-28, tradução nossa).

Ao se proibir a pornografia estereotipada, não com base na moral, mas no reconhecimento de dano coletivo em razão da exploração feminina, bem como do reforço da ideia de submissão/dominação, torna-se possível o reconhecimento de dano social e, consequentemente, estimula-se a ideia de que as mulheres não são meros objetos. Foi nesse sentido que Dworkin e MacKinnon elaboraram o projeto de lei visando proibir a produção, venda, exibição e distribuição de qualquer material definido como pornográfico (SILVA, 2013). O argumento foi proteger não apenas a mulher que está diretamente vinculada à indústria pornográfica, mas toda a coletividade de mulheres, que são vistas como objeto e sofrem o reflexo dessa visão na sociedade.

Nos Estados Unidos, o projeto foi aprovado pelo legislativo em Mineapólis (cidade do Minnesota) e vetado pelo prefeito. Em Indianápolis (estado de Indiana), o projeto tornou-se lei; no entanto, foi considerado inconstitucional pelo Sétimo Circuito de Apelações por ser considerado como censura e, consequentemente, como violador da Primeira Emenda. O Canadá, por sua vez, acatou em partes o projeto de Dworkin e MacKinnon, tornando típica a posse e distribuição de obscenidades, com exploração indevida de sexo, quando o ato sexual for mesclado com crime, crueldade, horror ou violência. Ao ser questionada a constitucionalidade do artigo na corte canadense, destacou-se que tais materiais colocam as mulheres em posição de subordinação, submissão e/ou humilhação, ferindo-se os princípios de igualdade e dignidade, sendo, o tipo penal, constitucional. MacKinnon atuou como amicus curiae nos principais casos envolvendo pornografia no Canadá (SILVA, 2013).

No mesmo sentido, a percepção sexista das relações de consumo expõe a mulher ao risco, tornando-a suscetível de sofrer as consequências de um dano existencial transindividual e compartilhado; ou seja, torna-a, potencial e constantemente, vítima preferencial a sofrer danos decorrentes do assédio de consumo perpetrado pelos agentes econômicos de mercado, em situação de hipervulnerabilidade, nos termos do CDC, em razão da desigualdade presente na relação (VERBICARO; ALCÂNTARA, 2017). 
Tais práticas são consideradas abusivas e atentatórias à consumidora em nível coletivo, uma vez que o gênero não pode ser considerado como um fator legítimo para discriminação feminina nas relações consumeristas.

Para Verbicaro e Alcântara (2017), a liberdade da atividade econômica não pode admitir a exploração da consumidora, sobretudo quando objetiva segregar por meio da discriminação de gênero. No mesmo sentido, para MacKinnon (1995, 2013, 2016) e Dworkin e MacKinnon (1988), a pornografia não pode ser considerada legítima apenas pela liberdade mercadológica, devendo ser combatida em face da discriminação de gênero, da quebra do princípio da igualdade e pelo reconhecimento da mulher como sujeito, e não apenas como mero objeto sexual para satisfação dos desejos masculinos.

A conscientização coletiva mediante o empoderamento cívico da mulher é uma forma de combate de práticas sexistas, conforme se observou nos casos discutidos no texto, em razão da reestruturação da consciência crítica feminina pela experiência social das mulheres, confirmando o método estabelecido por MacKinnon em sua teoria feminista.

\section{REFERÊNCIAS}

ALMEIDA, Rodolfo; MARIANI, Daniel; OSTETTI, Vitória. O imposto sobre absorventes no Brasil e no mundo. Nexo, [s. l.], 5 dez. 2016 (atualizado em 7 mar. 2017). Disponível em: https://bit.ly/2ROrvB9. Acesso em: 15 out. 2019.

ARENDT, Hannah. A Condição Humana. 10. ed. Rio de Janeiro: Forense Universitária, 2007.

BAROCELLI, Sérgio Sebastian. Towards the construction of "hyper-vulnerable consumers" category. In: MARQUES, Claudia Lima; PEARSON, Gail; RAMOS, Fabiana D’Andrea (ed.).

Consumer Protection: current challenges and perspectives. Porto Alegre: Orquestra, 2017.

BEAUVOIR, Simone de. O segundo sexo. Fatos e mitos. São Paulo: Difusão Européia do Livro, 1970.

BELTRÁN, Elena Pedreira. Justicia, democracia y ciudadanía: las vías hacia la igualdad. In:

BELTRÁN, Elena et al. (org.). Feminismos: debates teóricos contemporáneos. Madrid: Alianza, 2008.

BRASIL. Lei ${ }^{\circ}$ 8.078, de 11 de setembro de 1990. Dispõe sobre a proteção do consumidor e dá outras providências. Brasília, DF, Diário Oficial da União, 12 set. 1990, retificado em 10 jan. 2007. Disponível em: https://bit.ly/3CR3a0C. Acesso em: 15 out. 2019.

DWORKIN, Andrea. Pornography: Men possessing women. New York: A plume book, 1981.

DWORKIN, Andrea. Woman Hating. New York: A plume book, 1974. 
DWORKIN, Andrea; MACKINNON, Catharine A. Pornography and Civil Rights: A New Day for Women’s Equality. [S. l.: s. n.], 1988.

EMPRESA se desculpa por oferecer prêmio a russas que engravidassem de jogadores. O Estado de S.Paulo, São Paulo, 20 jun. 2018. Disponível em: https://bit.ly/3ayQhfl. Acesso em: 12 ago. 2019.

FREIRE OLIVEIRA-CRUZ, Milena. Representação feminina na publicidade: estereótipos, rupturas e deslizes. Chasqui. Revista Latinoamericana de Comunicación, [s. l.], n. 134, p. 181-200, 2017.

HARVEY, David. A produção capitalista do espaço. São Paulo: Annablume, 2005.

KYMLICKA, Will. Filosofia política contemporânea: uma introdução. Tradução Luíz Borges. São Paulo: Martins Fontes, 2006.

LA BOÉTIE, Étienne. Discurso sobre a servidão voluntária. Lisboa: Antígona, 2016.

LA PUBLICIDAD sexista de Carrefour en Argentina: ellos campeones y constructores, ellas cocineras y coquetas. elDiario.es, [s. l.], 1 ago. 2018. Disponível em: https://bit.ly/3nmQx6b. Acesso em: 12 ago. 2019.

MACKINNON, Catharine A. Desejo e poder. In: MIGUEL, Luis Felipe; BIROLI, Flávia (org.). Teoria política feminista: textos centrais. Vinhedo: Ed. Horizonte, 2013. p. 231-248.

MACKINNON, Catharine A. Feminismo, Marxismo, Método e o Estado: Uma agenda Para Teoria. Revista Direito \& Práxis, Rio de Janeiro, v. 7, n. 15, p. 798-837, 2016.

MACKINNON, Catharine A. Hacia uma teoria feminista del estado. Madrid: Edicines Catedra, 1995.

MORENO, Rachel. A imagem da mulher na mídia: controle social comparado. 2. ed. São Paulo: Expressão popular, 2017.

NOVAS, Karan. Ministério da Justiça instaura processo administrativo contra Devassa. Propmark, [s. l.], 4 out. 2013. Disponível em: https://bit.ly/3xOjgEy. Acesso em: 27 jul. 2019.

SAFFIOTI, Heleieth. Gênero patriarcado violência. 2. ed. São Paulo: Expressão Popular, 2015.

SANTANA, Léa Menezes de. “—- Tem pornô para mulher?”: uma abordagem crítica da pornografia feminista. 2014. 92 f. Dissertação (Mestrado em Estudos Interdisciplinares sobre Mulheres, Gênero e Feminismo) - Universidade Federal da Bahia, Salvador, 2014.

SILVA, Bruno Anderson Souza da. A profanação do Improfanável. O "Capitalismo como Religião” e uma reflexão ética a partir de Agamben. Porto Alegre: Editora Fi, 2018.

SILVA, Júlio Cesar Casarin Barroso. Liberdade de expressão, pornografia e igualdade de gênero. Estudos Feministas, Florianópolis, v. 21, n. 1, p. 143-165, jan./abril 2013.

SIQUEIRA, Camilla Karla Barbosa. As três ondas do movimento feminista e suas repercussões no direito brasileiro. In: BEDIN, Gilmar Antonio; CITTADINO, Gisele Guimarães; ARAÚJO, 
Florivaldo Dutra de (coord.). Poder, cidadania e desenvolvimento no estado democrático de direito [recurso eletrônico on-line]. XXIV Congresso Nacional do CONPEDI UFMG/FUMEC/Dom Helder Câmara. Florianópolis: CONPEDI, 2015. p. 328-354.

TAVARES, Ligia Maria Ladeira; LOIS, Cecília Caballero. Anotações sobre a teoria feminista do direito de Catharine MacKinnon. Revista de Gênero, Sexualidade e Direito, Curitiba, v. 2, n. 2, p. 151-170, jul./dez. 2016.

VERBICARO, Dennis; ALCÂNTARA, Ana Beatriz. A percepção do sexismo face à cultura do consumo e a hipervulnerabilidade da mulher no âmbito do assédio discriminatório de gênero.

Revista Pensamento Jurídico, São Paulo, v. 11, n. 1, p. 172-192, jan./jun. 2017.

VERBICARO, Dennis; FREIRE, Gabriela Ohana Rocha. A perda da influência estatal nas relações de consumo e a involução da proteção administrativa daí decorrente. In: ROVER, Aires José et al. (coord.). Direito, governança, novas tecnologias e desenvolvimento econômico sustentável, globalização e transformações na ordem social e econômica. Lefis series. Zaragoza: Prensas de la Universidad de Zaragoza, 2018b. p. 118-140.

VERBICARO, Dennis; FREIRE, Gabriela Ohana Rocha. O combate ao dumping social no mercado de consumo através do exercício qualificado da liberdade de escolha do consumidor. Revista de Direito, Globalização e Responsabilidade nas Relações de Consumo, Porto Alegre, v. 4, n. 2, p. 1-18, jul./dez. 2018a.

VERBICARO, Dennis; VERBICARO, Loiane Prado; AZEVEDO, Camyla Galeão de. A indústria cultural e o consumismo sob a perspectiva da mulher. Revista de Direito do Consumidor, São Paulo, v. 123, p. 77-106, maio/jun. 2019.

VIANNA, Cynthia Semíramis Machado. Da imagem da mulher imposta pela mídia como uma violação de direitos humanos. Revista da Faculdade de Direito UFPR, Curitiba, v. 43, n. 0, dez. 2005. 